\section{Reindeer in Scotland}

IN a written reply in the House of Commons on March 8, the Secretary of State for Scotland said: "I have informed the Reindeer Council of the United Kingdom through the Scottish Council (Development and Industry) that the Government are prepared, as an exceptional arrangement in view of the possible advantage to the Scottish economy, to authorize the import of 25 reindeer from Sweden so that an experiment to determine whether they can be usefully and successfully reared on a suitable site in the Highlands and islands may be carried out. The experiment would be subject to strict conditions which have been suggested by the Nature Conservancy and to animal health safeguards". On the previous evening an exhibition of reindeer products was opened at 14 Ladbroke Square, London, W.11, by Sir Frederick Whyte, chairman of the Reindeer Council.

\section{Astronomy in Ireland}

THE issue of the Irish Astronomical Journal for September 1950 (1, No. 3), like those that have preceded it, contains a number of interesting articles, the most important of which is Dr. E. J. Opik's contribution, "Interstellar Meteors and Related Problems". Dr. Ópik is convinced that many meteors have hyperbolic velocities and hence arrive in the solar system from interstellar space. $\mathrm{He}_{\Theta}$ devotes seventeen pages to an analysis of the observational results and gives a brief description of the rocking mirror which he devised at Harvard College Observatory to determine the velocities of meteors. Convinced that Porter's analysis of the hyperbolic velocities obtained during the Harvard College Expedition to Arizona to study meteors in general is open to serious objections, he quotes Dr. A. C. B. Lovell, whose work at Jodrell Bank, University of Manchester, on meteors, by utilizing radar, is well known. Two years ago, Dr. Lovell admitted that many hyperbolic velocities had been measured. (In an article in Discovery of January 1951, Dr. Lovell states that at present the radio measurements strengthen the case of those who believe that all meteors are members of the solar system.) In addition to a number of topics included under "News and Comments", Dr. M. Davidson has an article entitled "The Atmospheres of the Earth and Planets", which is a summary of a recent book by eighteen authors, edited by Prof. Gerald P. Kuiper (University of Chicago Press, and Cambridge University Press, 1949). Very important work was carried out over a period of some years by means of rockets capable of rising to heights of a hundred miles or more and dropping meteorological instruments during their descent. Richard Hayward (a well-known author on Irish life and scenery), in collaboration with John H. McElderry, has an article with the title "Astronomy Sixty Years Ago; The Ulster Astronomical Society 1890/94", which provides an excellent account of a Society that set out with high hopes and came to an untimely end. Judging by the interest in astronomy in Ireland at present, one can safely predict that there is no danger of the Irish Astronomical Society meeting with a similar fate.

\section{St. Ives Research Station of the Board of Green- keeping Research}

THE St. Ives Research Station at Bingley, Yorks, of the Board of Greenkeeping Research reports that in 1950 another year of successful progress was made.
The total number of advisory visits carried out was 1,135, as compared with 942 in 1949 and 752 in 1948 . Extended advisory tours were made in Great Britain and the Republic of Ireland, and visits were also paid to Sweden, Belgium, Holland and Switzerland. The figures for the correspondence of the Station show that in 1950 a total of 18,436 letters was dispatched (as against 14,821 in 1949 , and 10,243 in 1948), 11,306 being in answer to technical inquiries from affiliated clubs and organizations. On the educational side, a number of courses of instruction were arranged, and lectures and advisory talks continued to play a prominent part in the Station's outside activities. In September, a series of functions were held at the Station to mark its twenty-first anniversary (see Nature, September 16, 1950, p. 463). Pressure of work in the laboratory has inereased very rapidly since the end of the Second World War, 5,711 samples being analysed last year as compared with 4,492 in 1949 ; it was necessary, therefore, to take over another building adjoining the office block and convert it into a new laboratory. The increase in the activities also necessitated the appointment in August of two more advisory officers : Mr. G. R. Lewis, a graduate in agricultural botany of the University College of Wales, and Mr. J. D. Joss, who holds the diploma of horticulture of the University of Edinburgh and who for some time past has held a post in the Royal Botanic Gardens, Edinburgh.

\section{Colonial Plant and Animal Products}

THE main article in a recent issue of the journal of the Colonial Products Advisory Bureau (Plant and Animal, 1, No. 2 ; 1950 . H.M. Stationery Office) has been compiled by members of the staff of the Interdepartmental Committees of the Agricultural Research Council and of the Bureau and deals with natural and synthetic organic insecticides. Other articles deal with essential oils from Tanganyika; cinnamon bark from Seychelles; marama oil from Bechuanaland; tobacco from Mauritius; leaves and bark from Nigeria; tonka boans from Nigeria; aloes from the Leeward Islands; tingo fibre from Nyasaland; ginger from Sierra Leone; grain-cracks in hides ; and the drying of goat skins. Notes are also given on bamboo cultivation and utilization; the determination of pyrethrins in Pyrethrum flowers; the market in the United Kingdom for Colonial pig skins; and rice cultivation in the U.S.S.R. The journal also includes the usual book reviews and lists of recent books in agriculture and forestry.

\section{Production Control in the Small Factory}

THE BS 1,100 series-"Office Aids to the Factory" -was originally written for the British Standards Institution during the War to help firms engaged on armament production, particularly those entering this field for the first time. One of the series has now been revised by the British Institute of Management and published under the title of "Production Control in the Small Factory". The original books were written primarily in terms of the engineering industry ; but most of the information can be applied to any factory engaged on small. and medium-size batch production of fairly simple articles, whatever the industry. The extensive use of tabulation should make the booklet of value as a work of reference, especially for managers of factories employing fifty to two hundred people. The main revisions have been the elimination of sections on cost comparison 